\title{
PODER Y CONFLICTOS DE AUTORIDAD \\ EN SANTIAGO DE GUATEMALA DURANTE EL SIGLO XVI
}

Las explicaciones de los hechos históricos relativos al continente americano a partir de su conquista y colonización por parte de los europeos, se han basado casi exclusivamente en la acción de dos grupos antagónicos y complementarios: el blanco y el indio. Ello, sin dejar de ser útil para la comprensión del fenómeno general de la colonia, es insuficiente cuando atendemos a lac diferencias regionales, funaamentadas, en parte, en la conjunción de factores rnedioambientales y étnicos, pero también en el número y composición de la población blanca dominante y la temprana o tardía aparición del mestizo, quien debilitaría las fuertes barreras raciales y sociales establecidas legalmente entre la población autóctona americana y -en el caso que nos ocupa - los españoles.

Aquéllos que se establecieron en tierras americanas no constituían un grupo homogéneo, ni siquiera en los primeros años de la colonia; ya desde el siglo XVI los hallamos divididos y enfrentados disputándose el poder y la riqueza, escasa, por cierto, en Guatemala, si la comparamos con otras regiones de América.

La documentación relativa al primer siglo de vida colonial guatemalteca refleja ya el conflicto existente entre los intereses creados de los conquistadores, quienes se consideraban merecedores de toda clase de prebendas reales, y nuevos grupos de españoles, que exigían participar en el honor, la riqueza y el poder de aquéllos. Delegaios reales, mercaderes, comerciantes y nuevos pobladores en genera!, además de los representantes de la iglesia católica, especialmeinte los religiosos de una o varias órdenes, disputaban tierras, preeminencias 
y el dominio sub:e los indios a quienes habían puesto las tierras de Guatemala bajo el vasallaje de la Coronć.

Derechos, deberes y privilegios, perfectamente establecidos y delimitados por ley para los diversos grupos, fueron transgredidos una y otra vez en función de los iniereses que se deseaban proteger, recayendo sobre los indios ias iras o frustraciones de todos los españoles.

En las páginas que siguen deseo centrar iá atención del lector sobre los diversos grupos sociales que convivían en Santiago de Guatemala durante la primera centuria del período colonial, haciendo especial referencia a los factores que movieron a grupos e individuos a cuestionar la legitimidad del sistema de distribución de recompensas instituido en aquellas tierras; factores que procedían tanto del campo económico como del ideológico. El conflicto de intereses se mitigaría parcialmente a principics del siglo XVII, debido a las alianzas matrimoniales establecidas entre los descendientes de conquistadores y los comerciantes e hijos de las personas quie detentaban el poder político. En ambos casos, el dinero, el poder y la autoridad complementaron el honor y la honra adquiridos por los conquistadores y «sustentada» por sus descendientes.

\section{LA CIUDAD Y LOS BARRIOS INDFGENAS}

Santiago de los Caballeros, capital del reino de Guatemala, tuvo varios asentamientos desde su fundáción, el 24 de julio de 1524. El primero, en Iximché, fue abandonado por los españoles al mes de ser establecido por Pedro de Alvarado, debido al levantamiento de los cakchiqueles, que les hizo trasladarse provisionalmente a Olintepeque, cerca del actual Quetzaltenango. Tres años después de su primera fundación (1527), Jorge de Alvarado —que desempeñaba el cargo de teniente de gobernajor en ausencia de su hermano Pedro- llevó la ciudad a un lugar más favorable para la vida, el valle de Almolonga, al pie del volcán del Agua. La capital estuvo asentada en este lugar hasta el año 1541, en que los efectos de 
unas lluvias torrenciales la destruyeron cas1 pos completo. Después de este suceso, los vecinos buscan un nucre lugar donde ubicar la ciudad y eligen el valle del Tuerto - al que los indígenas llamaban Panchoy- a una legua de distancia de la recién destruida capital de Almolonga. El actc oficial de traslación tuvo lugar el 10 de marzo de 1543, fecha en que concejo, justicia y regidores, precedidos por los alcaldes, llegaron a Panchoy.

En diversas ocasiones grandes temblores de tierra hicieron peligrar la vida de la ciudad, con las consıguientes muertes de vecinos y destrucción de edificios, hasta que el 29 de julio de 1773 un terremoto de gaandes proporciones destruyó esta capital de Panchoy (hoy Antigua), quedando desde entonces establecida la ciudad en el lugar que actualmente ocupa.

La nueva ciudad de Santiago tue de las primeras capitales planificadas de América. En cste nuevo asentamiento había posibilidades de habitabilidad para cinco mil personas ${ }^{1}$, repartiéndose los sitios para vivienda de los vecinos en orden de importancia: los más cercanos a la plaza correspondieron a las personas más sobresalientes -antiguos conquistadores-; más alejados a ella se fueron ubicando los pobladores y en los alrededores de la ciudad, en las zonas que más tarde se llamaron barrios de San Francisco, La Merced y Sarito Domingo, se fueron estableciendo gran cantidad de incisos que, junto con los que poblaron en las milpas dil valle, trabajaban para los españoles en sus labranzas, obras públicas o servicio doméstico.

El valle de Guatemala (Panchoy) formaba parte de una circunscripción mayor, llamada por ics indígenas Pasuya y por los españoles corregimiento del Valle; éste englobaba a su vez otros nueve valles: Chimaltenango, Jilotcpeque, Alotenango, Zacatepequez, el ya referido de Guatemola o Panchoy, Mixco, Las Vacas, Canales y Petapa ${ }^{2}$. El corregimiento del

1 Annis, V. L.: The Arcbitecture of Antigua Guatemale. 1543-1573. Guatemnla, 1968, pars. 7. pág. 2.

2 Juarros, D.: Compendio de la Historia de la ciudad de Guatemala. Guaternala, 1963, 
Valle extendía su jurisdicción unas diez leguas alrededor cie Santiago y las pcblaciones indias writribuían ccn sus servicios al mantenimienio cie la ciudad ${ }^{3}$.

El historiador Juarros comenta acerca de las poblaciones indígenas cercanas a la capital:

"De estos pueblos se seguía gran utilidad a sus vecinos, pues en ellos hallaban copia do manos que emplear es sus laborei y abundancia de víveres y otras cosas necesarias para la vida o para el regalo. En efecto, el que necesitaba albañiles los encontraba en los pueblos de Jocotenango, Santa Ana y San Gaspar; santeros en Sari Cristóbal el Bajo; hortelanos en San Pedro de las Hucrtas; panaderos en Sarta Ana. Los de Santa Isabel eran cortadores de carnicerías; los de Almolonga proveían la plaza de Guatemala de multitud de frutas... los de San Cristóbal el Alto traían todo género de flores. Loz mismos de Almolonga y los de San Gaspar proveían la ciudad de pulque o vino maguey... Otros puoblos traían leña, carbón y cosas semejuntes" 1.

La mayoría de estas poblaciones indígenas del Valle se formaron en las tierras distribuidas a los conquistadores poco después de la fundación de la ciudad en Alınolonga. Estas tierras se poblaron con indios no reducidos que vivían dispersos en rancherías y a los que los españoles apresaban y asentaban en sus «milpas, labranzas y sementeras», a fin de que trabajasen en ellas. Asimismo, a los indígerias capturados en la guerra se les esclavizaba y gran número cie ellos, procedentes de lugares diversos, fueron llevados a Santiago por los vecinos de la ciudad para que trabajasen la tierra, cuidasen de sus ganados y se dedicasen a oficios artesanales ${ }^{\circ}$. Eran

3 Dos alcaldes ordinarios, elegidos cada año por el cabildo de Santiago, actuaban como corregidores seis meses cada uno. El corregidor tenl1 derecho a intervenir en todos los casos judiciales de los indios, que no implicascn mutilación o reiigro público. El corregidor recaudaba los tributos, vigilaba los repartimientos de mano de abra para la ciudad e inspeccionaba la agricultura. Esta juriedicción se dividió en dos alcaldlas mayores en 1753. Suñe, B.: Bl corregidor del Valle de Guatemala: una institución espafiola para el control de la poblactón indfgena. «Revista de la Universidad Complutense», XVIII, n.० 17, Madrid, 1979, págs. 153-168.

4 Juarros, D.: Compendio..., pár. 221.

5 A.G.I. Guatemala, 110. En una probanza realizada por el cabildo de Santiago (24 de mayo de 1531) se dice que los españoles van al Puerts de Caballos (Honduras), distante 25 leguas del Valle, aa tomar esclavos; sacan todos los esclavos que pueden y vuélvensex. 
tantos los indios establecidos ai servicio de ios españoles en la ciudad que cuando se destruye la prinıera Santiago, en 1541, mueren dentro de ella «más de seiscientos indıs, además de negros y algunos mestizos» ${ }^{\circ}$. Esta cifra adquiere mayores proporciones si la comparamos con la publación hispana de la ciudad: en ella sólo había edificadas ciento cincuenta casas de vecinos.

Después del traslado de la ciudad al valle de Panchoy, vuelven a distribuirse tierras que, asimismo, se transforman en asentamientos indígenas. Con la liberación de los esclavos en $1549,{ }^{7}$ el número de indios establecidos dentro y cerca de la ciudad aumentó pues, aunque algunos de los emancipados volvieron a sus lugares de origen, muchos siguieron viviendo en tierras de sus antiguos amos y ocros, ayudacios por los religiosos, se asentaron en la periferia de Santiago formando barrios, algunos de los cuales tomaron los nombres de las órdenes religiosas establecidas en 1a ciudad: San Francisco, La Merced, Santo Domingo... Los pieblos indígenas que se fundaron en el Valle, en cambio, se bautizaron con el nombre de un santo y el sobrenombre de la familia dueña de la tierra; éste fue el origen de pueblos como San Gaspai Vivar, porque se pobló con antigros esclavos de Diego de Vivari, Santa Catarina Barahona, fundado en las tierras de Sanche de Barahona, o el de Santa Catarina Bobadilla, congregado por Ignacio de Bobadilla ${ }^{8}$.

No conocemos con exactitud el número de habitantes in-

6 A.G.I., Patronato, 181, N.0 1, R.० 2. Relación ha ha por el obispo Marroquin sobre la destrucción de Santiago en 1541. 10 de septiembre de 1541.

7 A.G.I., Guatemala, 965. Testimonio para que conste que dieron por libres los indios. 1551. Aunque las Leyes Nuevas se promulgaron en 1542 y en ellas sc estriblecla la abolición de la esclavitud y el trabnjo forzado de los indios, en Guatemala no fueron aplicadas hasta la llegada del presidente Cerrato. El historindor C. H. Lutz calcula que fueron puestos en libertad entre 3.000 y 5.000 indion asentados en el Valle y ciudad de Santiago. Historte sociodemográfica de Santiago de Guatemala. 1541-1773. Guatemala, 1982, pdig. 95.

8 Otros pueblos con el mismo origen son: Sin Butolomé Carmona, Santineo Zamora, San Miguel Escobar, Santa Lucla Monterroso, San Juan Gasciss, San Lucas Cabreta, Santa Isabel Godinez, San Lorenzo Monroy y San Bartolomé Becerta; fundados en tierras de Juan Carmona, Alonso de Mora, Juan de Escobar, Prancisco de Monterroen, Gascón de Guramán, Cristóbal Cabrera, Diego Monroy y Bartolomé Becerra, respectivamente. Juarms: Compendio..., pdisa. 222-223. 
dígenas que llegó a tener el valle de Panchoy y el corregimiento del Valle durante la época colonial. Las cifras de población con las que contamos están basadas en partidas de tributarios y en el caso del corregimiento del Valle estas tasaciones resultan muy incompletas; no olvidemos que gran parte de esta población estuvo dispensada del tributo durante algún tiempo (mexicanos auxiliares de la conquista, antiguos esclavos y naboríos liberados) ${ }^{\circ}$, además de que, a veces, no quedan plasmados en las listas de tributarios el número de viejos y enfermos o de indios dedicados al servicio de la Iglesia, quienes, asimismo, estaban exentos de tributar. Por ello, el censo realizado por el presidente Cirrato on 1549 aporta una información muy incompleta sobre el Valle. En 1567 existen mil seiscientos cuarenta y cinco tributarios en el corregimiento y la tasación mandada hacer por el presidente Valverde en 1584 arroja un total de mil doscientos noventa y ocho tributarios ${ }^{10}$.

En cuanto a la población españoia ubicada en la ciudad, los documentos nos hablan de doscientos seteita y siete vecinos entre los años 1572 y 1577, lo que la convierte en la ciudad más poblada del reino de Guatemala, seguida de San Salvador y Ciudad Real de Chiapas (130 y 180 vecinos respectivamente) ${ }^{11}$. En 1591 su población casi se había doblado -cuatrocientos cincuenta vecinos-y en 1604 alcanza ya la cifra de setecientos cincuenta vecinos. Por último, en la descripción que Vázquez de Espinosa nos ofrece de la ciudad en

9 A los indigenas que residfan en las milpas del Valle y en los barrios urbenos no se les oblige a parar tributo hasta mediedos de 1560. Lutz: Historia..., phes. 158. Al igual que los eaclavos, los indios naborlos (o laborfos), sirvientes heredirarios asignado. individualmente a los vecinos espanoles, fueron sacados de diverses regiones 5 establecidos en los alrededores y dentro de la ciudad. Desputs de la destrueción de Santiago en Almolongs, eatos sirvientes se trasladaron con sus amos espanoles a la nueva ciudad en Panchos. Con la ejecución de las Leyes Nuevas los naborlos obtuvieron la libertad y se establecieros en los nuevos barrios, entre los entiguos esclavos indios. Lutz: Historia..., phes. 96

10 Lutz: Historia..., phis. 158.

11 A.G.I., Indiferente General, 1.528. Relación de los vecinos y encomenderos de la Gobernación de Guatemala, 1572-157. 
1620 señala que viven en ella «más de mil vecinos españoles, muchos esclavos negros y muchos indios de servicio» ${ }^{12}$.

Santiago fue sede de la audiencia desde 1549 a 1573; con excepción de unos cuantos añcs que ésta permaneció en Panamá (1563-1570), toda América Central y Chiapas, es decir, todo el territorio conocido como «Reino de Guatemala», se gobernó desde dicha ciudad. Asimismo fue cabeza del obispado de Guatemala desde el año 1534, en que ostenta la dignidad cardenalicia don Francisco Mar roquín.

Los relatos históricos y los restos artísticos nos hablan de la relevancia que la capital guatemalteca fuc adquiriendo a través de los años. La ciudad se pobió de casas solariegas al estilo español de Santander o Andalucía, con gran boato de mobiliario, jardines, caballerizas y coches. Desde aquellos primeros años en que se reducía a un pequeño núcleo urbano y unos cuantos barrios de indios en torno a él, se llegó a la conformación de uná gran ciudad en la que la población española (siglos XVII y XVIII) se expanđía a las zonas irdígenas y se creaban nuevos barrios 'donde convivían españoles, indios, negros, mulatos y mestizos. En el primer cuarto del siglo XVII Santiago contaba ya con tres monasterios de frailes (mercedarios, dominicos y franciscanos), uno de monjas, dos iglesias parroquiales (catedral y San Sebastián), un hospital de pobres y dos colegios: el «Seminario para crianza de los niños nobles» y el «Colegio para recogimiento de doncellas pobres o hijas de padres ricos» ${ }^{\mathbf{1 3}}$.

A fines de la primera cencuria de su existencia como capital colonial, Santiago contaba ya son tres princıpales vías de comunicación con el exterior: el camino de Petapa, que unía

12 A.G.I., Patronato, 183, R. 2. Relación hecha por Juan Balutista Ar.tonelli y Diego López de Quintanilla de la ciudad de Guatemala, 1591. Archivo General de Centroamérica (en adelante A.G.C.) A1.1804.11810, Becerro de las cuadras de Antigua Guatemala, 1604. Várquez de Espinosa, Fr. A.: Compendio y descripción de las Indias Occidentales, Washington D.C., 1948, pág. 204. Para llegar a un cálculo más aproximado del número de habitantes de Santiago, hay que tener en cuenta que el término «vecino» equivale a «cabeza de famllia» (por lo que no se contabilizan mujeres y niños o hijos solteros), además de que la numerosa población eclesiástica (regular y secular) no se incluye en estos cálculos.

13 Vázquez de Espinosa: Compendio..., pág. 202. 
Santiago con la mayor parte de los pueblos del Valle, siendo también vía de conducción de las mercacerías que llegaban del Golfo Dulce; el de Jocotenango, por el que entraban las mercancías de México, Oaxaca y Chiapas; y, finalmente, el de Ciudad Vieja, que comunicaba la capital con Suchitepequez y Soconusco ${ }^{14}$.

Cuando Santiago de los Caballeros fue destruida por el terremoto de 1773, el núcleo principal de ella sc componía de dieciséis barrios, sin contar con los dc Jocotenango, al norte y Santa Ana, al sur; rodeando la ciudad, y bastante cerca para proveer a su mercado diario, sc extendían veinticinco 'pueblos o aldeas de indios. La capital guatemalteca había aumentado su extensión para esta fecha en cinco veces su tamaño original, ucupando un área otho o diez veces mayor que la establecida en la traza de $1541^{1}{ }^{1 .}$.

\section{Grupos Raciales}

y estratos sociales en Santi.jgo

A pocos añus de la conquista. la población: guatemalteca se dividía en dos grupos cerrados -españoles e indios-, con derechos y deberes, penas y castigos legalmente establecidos para cada uno de ellos; sin embargo, ninguno de tlos constituía un grupo homogéneo.

La funcionalidad y valoración de los roles o actividades sociales y la mayor o menor antigüedad en la tierra, constituyeron criterios determinantes de posición sociul entre la población española .En cuanto a los i..ndígenas, aunque en zonas alejadas de la ciudad siguieron mantentendo, pcr algún tiempo, una estructura social interna semejante a la que existía en época prehispánica, en el valle y tierras cercanas a la capital, las preeminencias concedidas por la Corona española a los an-

14 Fuentes y Guzmán, F. A.: Historia de Guatemala o Recordación florida. Madrid, 1972, pág. 163.

15 Annis: The Arcbitecture..., pág. 10. 
tiguos señores indios les fueron prontamente arrebatadas por mestizos o indígenas ladinizados, es decir, indios «macehuales» o «del comúri » que ya hablaban castellano y mostraban un cierto grado de aculturación en sus formas de vida y comportamientos.

El desempeño de un papel tan importante en los primeros años de la colonia como el militar, colocó a los conquistadores en una posición superior con respecto ai resto de la población española, estratificándose ésta a su vez - de acuerdo con su mayor o menor antigüedad en la tierra - en poblacores antiguos y meros vecinos. El haber participado en la conquista, poniendo armas y caballos al servicio del rey, es motivo de encumbramiento para muchos españoles, quienes llegan a adquirir la categoría de hidaigos en aquella sociedad en formación ${ }^{16}$; la Corona les premia con encumiendas, ayudas de costa y cargos concejiles y, en ocasiones, lcs concede privilegios que los iguala a los hidalgos penınsulares. Es tan importante el guerrero en los primeros años de la colonia que, jncluso dentro del estrato constituido por los oficiales /de cficios mecánicos o meros vecinos se concede la mayor importancia social a los armeros, pues siendo las armas principal atributo dei caballero, es lógico que se intente favorecer a los individuos que hacen posible que aquél las porte ${ }^{17}$. Por encima de los conquistadores sólo se situarán en los primeros años los representantes del poder político y el poder religioso: los presidentes-gobernadores y los obispos.

Al igual que los conquistadores, los antiguos pobladores disfrutaron de cicrtos beneficios: conıo aquéllos, recibieron lotes de tierra que convirtieron en labranzas y haciendas de ganado gracias al trabajo de los ir.dios; en muchos casos obtuvieron encumicridas, tanto por estar casados con hijas o viudas de conquistadores como por haber participado en la

16 Para una mayor información sobre los conquistadores-hidalgo:, consultar mi trabajo sobre: Los bidalgos de Guatemala. Realidad y apariencia en un sistema de valores. Sevilla, 1976.

17 Remesal, A.: Historia General de las Indias Occidentales y particular de la Gobernación de Chiapas y Guatemala. Guatemala, 1966, T. I, pág. 73.B 
pacificación de regiones, como Pochutla y Lacandón, alzadas contra el dominio español después de la conquista. A veces consiguieron cargos concejiles y corregimientos y, en caso de extrema necesidad, recibieron las ayudas de costa que la Corona destinaba a «conquistadores pobres o viejos y tullidos» y a las viudas de unos y otros. Desde la década de los sesenta hallamos también recompensados con taies ayudas de costa o «pensiones en corregimientos» a personas pobres con título de licenciado o doctor - preceptores de gramática, médicos, etc.-, así como a monjas y beatas ${ }^{18}$; sin embargo, nunca se permitió que los «oficiales de oficios mecánicos» se beneficiaran de ellas y si alguna excepción se hace es por la necesidad que de estos «oficiales» se tiene:

"A Miguel de Aguirre, vecino de esta ciudad de Santiago de Guatemala, ciento cincuenta pesos de ayuda de sosta. Dáscle, aunque es pintor, porque es provechoso para el culto divin y porque ha hecho y hace mucho fruto para ello, por la razón arriba dicha" ${ }^{19}$.

La escasez de estos oficiales en los primeros años de vida colonial trajo como consecuencia su cxcesiva valujación y, consecuentemente, ellc les permitió scmeter múltiples abusos. Incluso llegan a amenazar con dejar desasistida la ciudad si no se les conceden encomiendas; una vez conseguidas, empiezan a vivir como «caballeros», manteniénáose. sólo con los beneficios de sus repartimientos y abandonandc sus oficios, por lo que en 1534 el cabildo decide quitarle los indios y apremiarles a que usen sus oficios ${ }^{20}$.

Pese a sus intentos de enncílecimiento, los artesanos y «oficios» formaron un estrato peirieciamente diterenciado del de los conquistadores, antiguos pobladores y sus descendientes - al menos durante casi los dos primeros siglos de vida

18 A.G.I., Guatemala, 55. Fe dada por el escribano de cámara de S.M. de algunos corregimientos y pensiones en corregimientos, así como de ayudas de costa a personas necesitadas, 14 de marzo de 1577.

19 A.G.I., Guatemala, 9. Relación de los oficios, cur.egimientos y ayudas de costa que el presidente Landecho ha proveido este año. 1 de febrero de 1563.

20 Remesal: Historia..., T. II, págs. 435.436. 
colonial- ocupándose éstos de controlar las ambiciones de aquellos desde sus puestos de cabildo, regulando sus jornales y los precios de sus manufacturas e incluso manteniendo el privilegio de examinar a los nuevos artesanos ${ }^{21}$. Sin embargo, la mayor necesidad de ciertos oficios e, incluso, la riqueza de los materiales que se trabajan, van a producir un escalonamiento interno del estrato, anteponiendiose o concediéndosele mayor prestigio a algunos oficios durante algunos años. Así, por ejemplo, la importancia que tenian los a.rmeros en los años que siguieron a la conquista se ve reflejada en las ordenanzas del cabildo sobre el lugar que han de ocupar los distintos «oficios» en la procesión del Corpus Christi, detrás de la Custodia: los más cercanos los armeros, después los plateros y mercaderes, seguidos de barberos, sastres, carpinteros, herreros, zapateros y demás artesanos ${ }^{\prime \prime \prime}$.

Avanzado el siglo e innecesarias ya las actividades guerreras en aquella sociedad, las aspiraciones de robleza de gran parte de la población española, reflejadas en el comportamiento y la «apariencia honrosa», convertirán en importantes a los individuos que hacen posible la distinción externa de los caballeros: en primer lugar los mercaderes «de grueso» o de «mercaderías de Castilla», seguidos, naturalmente, de plateros y sastres. Tanto unos como otros, imprescindibles desde los últimos años del siglo XVI, se enriquecerán y llegarán en algunos casos a ascender en la escala social hasta equipararse con los descendientes de conquistadores y antiguos pobladores, e incluso se unirán en matrimonio con las hijas de aquéllos.

Los indios, declarados vasallos libres y súbditos de la Corona, siguieron manteniendo en lugares lejanos a la capital - como ya dije- una estructura social interna semejante a la que existía en época prehispánica. Los caciques y principales tueron exentos del tributo, siguieron gubernando a sus propios

21 Por cédula del 10 de marzo de 1566 se mantiene al cabildo en el privilecio de exa. minar a los oficiales de sus oficios. Las primeras ordenanzas dictadas por el ayuntumiento para la constitución de los gremios de herreros y sastres son de 1530.

22 Remesal: Historia.., T. I, págs. 87 y 88. 
pueblos y se les concedió el status de hidalgos; los macehuales, en cambio, no habían de tributar a sus antiguos señores, sino al rey castellano y al encomendero, debiendo realizar asimismo toda una serie de trabajos forzados. Tanto principales como macehuales fueron considerados «menores» por las leyes españolas y esto les permitía gozar de una protección especial; así, la Inquisición no tuvo sobre ellos jurisdicción alguna, estaban exentos de pagar diezmos y alcabalas, no tenían que prestar servicio militar " se les prohibía usar armas de fuego o espadas y montar a caballo.

En el valle y tierras cercanas a ia capital de Guatemala la situación de los indígenas, sin embargo, era algo diferente; el mayor contacto con los españoles modificó un tanto la estructura social prehispánica. Los indics asentados en las tierras y milpas de los primeros vecinos de Santiago habían sido sacados de lugares diversos y no eran dirigidos ya por sus antiguos caciques, sino por mestizos o indios «ladinos en lengua castellana», gente que ya mostraba un cierto grado de aculturación en sus formas de vida y comportamientos. Por otra parte, no todos los indios que vivían en el valle tributaban; tanto los indios mexicanos que habían ayudado a Alvarado en la conquista como los natiguos esclavos liberados por las Leyes Nuevas fueron exentos del tributo. En cualquier caso, el trabajo de unos y otros indígenas - tributarios o no- vino a cubrir las necesidades y ambiciones de encomenderos, alcaldes corregidores, frailes, curas y vecinos de la ciudad.

En los primeros años de la colonia el ejercicio de las artesanías fue privativo de los españoles; los únicos oficios que los indios desempeñaban eran los que ya ejercían antes de ser dominados: los de petatero, ollero, aserrador, carpintero... A principios del siglo XVII, en cambio, los barrios de San Francisco y Santo Domingo se llenaron de cordoneros, albañiles, carpinteros y hasta algún que otro sastre indios; sin embargo, los «conciertos» de aprendizaje y contratos de trabajo especifican siempre ser ladinos en lengua castallena los que contratan sus servicios como oficiales o se conciertan con al- 
gún español para aprender un oficio. Nc obstante, algunos gremios mantuvieron cierto exclusivismo durante bastante tiempo; así ,sabemos que los plateros y armeros no concedían la maestría a negros ni indios.

Continuas cédulas reales regulun el trabajo de los indios y señalan la obligación que tienen los españoles de pagar sus servicios; éstos, en cambio, incumplían las leyes reales una $y$ otra vez y, si pagaban su trabajo a aquellos, fuese como artesanos o como trabajadores agrícolas, lo hacían muy por debajo de lo establecido por la ley.

Los primeros negros que pasaron a Guatemala lo hicieron como esclavos en compañía de sus amos (presidentes, oidores y otros cargos públicos). Aquellos venían a desempeñar una doble función; por una parte, constituían el servicio doméstico en casa de sus dueños; por otra, fundamentaban el prestigio socia! de éstos, consolidados sus status. Hasta tal punto llegaron a ser símbolos de posición social que, una vez desaparecidos los esclavos indios, conquistadores y antiguos pobladores - la gente importante de la ciudad - adquirieron numerosos negro; y negras para el servicio de sus casas, pese a que podían contar con el abundar.te y casi gratuito servicio de los indios.

Al finalizar el siglo XVI encontrimos ya esclavos negros hasta en las casas de los oficiales de oficios mecánicos, aunque en este caso cumplían una función netamente económica, ya que no se les dedicaba a realizar los quehaceres domésticos, sino a ayudar en su oficio a sus dueños o, incluso, se les alquilaba a otras personas. Por estas fechas, el grupo racial negro -constituyendo el grueso del servicio permanente de las casas- debió ser muy importante en la composición étnica de la ciudad de Santiago ${ }^{2.3}$. Sin embargo, el servicio de los indios no disminuyó, acudiendo semanalmente desde los pueblos con-

23 A.G.C., A1.4080.32397. Esto no sólo corrobora la información que aparece en un pleito; en su testimonio una negra esclava dice que «tardó mucho en hacer la compra porque habla muchas negras comprando». Autos contra Mary Gómez. 
tiguos a la ciudad, agrupándose en la plaza o «tianguez» del barrio de Santo Domingo a la espera de ser repartidos a los españoles, quienes los empleaban principalmente en trabajos agrícolas y en las haciendas de ganado ${ }^{24}$.

Como los negros, muchos mulatos - procedentes de la unión de españoles con esclavas negras - permanecieron en esclavitud; otros, en cambio, fueron libres desde su nacimiento, puesto que sus madres habían sido liberadas antes de que ellos nacieran. Estos mulatos, con el tiempo, vinieron a engrosar el número de los artesanos o fucron contratados por los dueños de estancias de ganado, desempeñando en ocasiones el cargo de mayordomos.

Negros, mulatos y zambos libres fueron a veces igualados por la ley. Aunque nunca permanecieron bajo el régimen de encomienda, sobre ellos - como sobre toda la población indígena asentada en el valle - recayó un impuesto especial destinado a beneficiar exclusivamente a ‘á Corona: el «servicio del tostón»; pero, mientras que los indígenas tributaban sólo un tostón de plata, negros, mulatos y zambos habían de pagar cuatro.

Ya en el siglo XVII un gran número de estos negros y mulatos llegaron a constituir la población flotante de Santiago y sus alrededores. Eran, en expresión de la época, cimarrones o furtivos; es decir, carecían de lugar fijo de residencia y solían trabajar únicamente por temporadas sirviendo a los españoles bien en sus casas, bien en las haciendas de ganado, trapiches de azúcar u obrajes de añi!. Adquirieron tal fama de alborotadores y pendencieros que los indígenas temían que entrasen en sus pueblos, va que les robaban víveres e incluso les quitaban sus mujeres; en la ciuciad de Santiago llegó a prohibírseles ei uso de armas por temor á que pudieran causar males y escándalos ${ }^{25}$.

24 A.G.I., Guatemala, 10. Repartimiento de los indios tequitines.

25 «Autos con diversas instrucciones de gobiernow. 1603. A.G.C. 1598.2216. Sobre el servicio del tostón en el Valle de Guatemala, consultar mi trahajo sobre: Cambio en la es. tructura familiar indigena. Influencias de la Iglesia y la eicontienda en Guatemala. En: Economis y sociedad en los Andes y Mesoamérica. Madrid, 1979, págs. 169.191. 
Sin embargo, no todos los negros y mulatos libres fueron cimarrones; como ya dije, muchos se integraron con la población de Santiago y, asentados en los barrios tradicionalmente indígenas, formaron parte del sorvicio de los españoles o desempeñaron algunos oficios.

Los mestizos gozaron de cierta siruación privilegiada con respecto a los mulatos, pues no sólo estaban exentos del tributo sino que, además, se les eximía del servicio del tostón; no obstante, también como aquellos estuvieron discriminados en lo que concernía al desarrollo de ciertas actividades sociales. En último extremo, su posición en la sociedad dependía de la de sus progenitores $\mathrm{y}$, a su vez, del interés que éstos hubieran mostrado por sus hijos naturales. Por ello, algunos siguieron formando parte de las comunidades indígenas a la que pertenecían sus madres, otros fueron a engrosar el número de los cimarrones y muchos aprendieron diversos oficios y llegaron a ser maestros, incluso en las artesanías que habían sido privativas de los españoles duranie los primeros años de la colonia ${ }^{2}$. Pero, si los mestizos aran hijos de conquistadores o pobladores antiguos $\mathrm{y}$, por añadidura, descendientes por vía materna de caciques indios, aquellos llegaban a formar parte de las casas principales, siendo rriados y educados por sus padres y las mujeres legítimas españolas de éstos; aún más, se comportaban como caballeros o damas «honradas», heredaban bienes de sus padres y, en casos excepcionales, llegaron a recibir encomiendas, además de contraer matrimonio con mujeres y hombres españoles ${ }^{27}$. En estos casos era el status de los padres lo que prevalecía sobre el criterio racial para

26 A.G.C., A1.540. Ya en el siglo XVII hny sastres mestizos y en un documento del año 1619 aparece información sobre un platero mestizo que vivla en la ciudad de Santiago. 'Testamento de Juan de Salazar, 1619.

27 A.G.I., Patronato, 75, R.o 2. Constituye una excepción el caso de dofia Leonor de Alvarado, mestiza, hija de doña Luisa Xicontecatl, hermana del seneral tlazcalteca. Esta mestiza casó en primeras nupcias con don Pedro Portocarrero y en segundas con el cuńado de su padre, don Francisco de la Cueva. Otro caso excepcional fue el de un hijo del conquistador Sancho de Barahona y de uuna mujen de la tierraw; el mestizo participo en las batallas de Pochutla y Lacandón, recibió un repartimiento de indios y se casó en Castilla. 
determinar la pusición social de loss mestizos; y es también la situación de los padres la que ileride la inclusión de los mestizos en las cofradías de españoles, así como el ingreso en el colegio-seminario de la Asunción de Santiago. fundado por el obispo fray Gómez de Córdoba er: $1596^{20}$. Sin embargo, las constituciones del colegio creado para «recogimiento de doncellas pobres ¿ pupilas ricas» (año 1592) son mucho más estrictas, ya que en ellas se especific`^ que no ha dársele entrada a ningund mestiza ${ }^{29}$.

Las diferencias raciales y la posición de los individuos en la sociedad yıatemalteca quedan perfectamente reflejadas en muchas disprosiciones legales; sólo pondré como ejemplo la disposición relativa a la prohibición de desjarretar ganado y las penas que se estabiecen para cada uno cie los giupos que componían aquella sociedad. En ella sa marcan las diferencias entre blancos y otras razas por una partc y, dentrc ya de estos dos grandes grupos, entre indios y «c,tras generaciones» por un lado y españoles importantes frente a meros vecinos, por otro. Así, ningún español recibe pena corporal si transgrede la norma, mientras que se prescribe ésta para los otros grupos raciales que lo hagan. Pero, mientras que el español dueño de ganado que infringe la ley ha de pagai una multa de trescientos ducados y cumplir un destierro de dos a cinco años, el esfañol de humilde condición es castigado con pena de vergüenza pública y ha de pagar una multa de cien ducados para la Cámara Real. Las diferencias entre indıos y «otras generaciones» se manifiestan en el hecho de que aquéllos sólo serán penados con cincuenta azctes, mientras que negros, mulatos, mestizos y zambos recibirán entre cien y doscientos. En caso de reincidencia ,el español sufrirá el destierro perpetuo de «todas las Indias», mientras que a nestizos, negros, mulatos

28 Archivo del Palacio Arzobispal. Guatemala. Negros. mulatos e indígenas tenían sus propias cofradías. «Libro de la fundación y Constitucionss del Colesio-Seminario de Nuestra Señora de la Asunción de Guatemala». 24 de agosto de 1596.

29 A.G.I., Guatemala, 58. Solicitud de aprobación del Colegio de Doncellas, 1592. 
y zambos se les duplica la pena corporal, siendo además condenados a «galeras al remo, tiempo de cinco añes» ${ }^{30}$.

PODER Y ENCOMIENDA:

CONQUISTADORES Y GOBERNANTES

Al finalizar los hechos guerreros, que m:iterializaron la conquista, los individuos que la hicieron posible mantenían una fuerte conciencia de grupo, adquir: da en la lucha y corroborada por la obiención de encomiendas cencedidas por la Corona para premiar sus esfuerzes.

Los beneficios producidos por la conquisıa los reclamaban para sí aquéllos que en verdad los habíar conseguido con su esfuerzo físico y económico, los conquistaciores; pero los restantes grupos sociales no se sonfcimaron con el simple papel de moderaciores, dirigentes y evangelizadores; de ahí la rapidez con que se crearon fuertes tensiones en torno a dichos beneficios. Pronto se engendraron grandes intereses en torno al indio y el conquistador entró en competencia con el resto de la población. La encomienda constituyć un fundamento de la hostilidad entre los conquist.?dores y el resto de la sociedad guatemalteca, junto con la hidalguía o beneficio de orden social. En torno a estos dos factores económico-sociales fluctuaron las relaciones antagónico-amistosas re los conquistadores con respecto a gobernantes, oficiales reales, clérigos, religiosos y los restantes vecinos de la ciudad.

Hay, dentro del grupo racial islanco, personas que se consideran «más honradas» y de «más calidad» que otras: son los conquistadores y sus descendientes. Las expresiones escritas de todos ellos están fuertemente cargadas de locucio-

30 A.G.C., A1.1589.2216. Las penas corporales establecidas para los delincuentes indios son siempre menores que las aplicadas a negros, mestizus, mul atos y zambos. Estas aparecen en multitud de documentos promovidos con ocasión de cieitos acontecimientos delictivos como asesinatos, latrocinios, o, simplemente, incumplimiento del pago ciel tributc. Libro con diversas instrucciones de gobierno. Prohibición de la desjarretadera para la conservación del ganado vacuno. 
nes valorativas sobre su situación en la escala social frente al resto de la población. En gran número de documentos (especialmente probanzas de méritos y servicios) ímplicita o explícitamente se hace referencia a la distancia que les separa de los restantes grupos sociales; juicios sobre su nobleza, su honra, su desprecio del trabajo manual, les hacen aparecer como las personas más importantes en la sociedad guatemalteca del siglo XVI. Se consideran nobles, hombres y mujeres principales y así lo expresan siempre que hay oportunidad para ello:

"Muestra su nobieza en el trato de su persona, casa y conversación" B1.

Manifiestan ante los demás su superioridad en cualquier ocasión: en las disputas, con motivo de cualquier acción delictiva, ante la justicia para hacer valer su inmunidad... ${ }^{32}$ y cuando a uno de estos hidalgos notorios, descendiente de conquistador y empobrecido, se le pregunta en un juicio cuál es su oficio, él responde ofendido que «el oficio que tiene es sustentar armas y caballos para servir a Su Magestad» ${ }^{\mathbf{3 3}}$.

Pero, si la superioridad social de los conquistadores sobre el resto de la sociedad es claramıente percibida por ésta y no se cuestiona, los gobernantes, en cambio, muestran una clara rivalidad con aquéllos, despraciındo su posición y, a veces, los hechos en los que cimentan su notoriedad. Cierto es que los representantes del poder político detentan la autoridad que el cargo les confiere, sin embargc, ven frecuentemente debilitarse su poder ante el fuerte grupo social de los conquistadores. Documentación diversa refleja el antagonismo entre éstos y los gobernantes, no súlo por cuestiones económicas (encomiendas) sino sociales (hidalguía, nobleza, status).

31 A.G.I., Patronato, 66, N.॰ 4, R.॰ 7. Expediente de Francisco Hernández de Illescas, 164. A.G.I., Patronato, 73, N.॰ 2, R.॰ 64. Información de don Rodrigo de Fuentes, 1574.

32 A.G.C., A1.4081.32383. Autos contra Juan Méndez de Sotomayor y Catalina de Salinas por illcita amistad, 1585.

33 A.G.C., A1.4074.32338. Pleito entre Francisco Vázquez y Francisco Alemán sobre 1a cuestión que hubo con Diego Hernández, teniente de alguacil de gobernación, 1573. 
La distribución de riqueza, poder y statis entre los habitantes de Santiago, fundamentada - romo ya he dicho- en la participación $\epsilon$ n la conquista y la intigüedad en la tierra, era frecuentemente ignorada por los representantes del poder político que consideraban injusto el sistema $\mathrm{d} \epsilon$ : gratificaciones establecido por la Corona; llegaron a cuestionar la legitimidad de dicha distribución, considerándose a sí mismos y a sus parientes con derecho a participar en los beneficios económicos destinados a los conquistadores. Sus abusos de autoridad les llevan a hacer caso omiso de las normas vigentes y de los privilegios concedidos por la Corona a aquéllos, disfrutando de beneficios en la tierra que gobernaban y distribuyendo encomiendas y repartimientus entre sus parientes, criados y amigos. Los conquistadores, por su parte, perciben este ataque a su posición como un ataque al orden social y acusan una y otra vez ante el rey el neipotismo de sus mandatarios.

Efectivamente, los gobernantes no desaprovechan ocasión de medrar en las riquezas y señorios que proporcionaban las tierras conquistadas; así, quitan y conceden indios a su antojo, aunque las leyes reales prescribían el reparto de indios y tierras atendiesıdo a la «calidad» de las personas. Ello hará que los conquistadores, sintiéndose agraviados, denuncien una y otra vez dichas arbitrariedades ante el rey. Acusaciones como la que transcribimos, hecha por el conquistador Innacio de Bobadilla contra el obispo Marroquín -en el período en el que fue gobernador provisional- las hallamos en boca de conquistadores y descendientes durante tuda la centuria:

"Repartió ia ticrra y pueblos vacos a persoras reciér venidas a la tierra, sin haber conquistado en ella, no guardando la orden y cédula do S.M. que sobre esto tienc dada, en que declara que sean preferidos los conquistadores en lo que vacare a otra persona. El señor obispo tomó para sí y para la Iglesia un repartimionto que llaman Atitlán y sus sujetos..." 34.

34 A.G.I., Putronato, 78, N. 2, R.o 1. Expediente de Diego Ordéñez de Villayzán, 1599. 
Uno de los primeros conquistadores, al cienunciar a don Francisco de la Cueva, teniente de gobernador (1541) nos da la posibilidad de ahondar en otro ile los problemas derivados de los intereses creados en torno a las encomiendas, a las relaciones conquistadores-gobernantes y a la maripulación por parte de éstos deì resto de los vecinos de Santiago, fundamentada en los beneficios económicos que los representantes del poder político prometían o repartían e.itre ellos. El conquistador denuncia el haber sido desposeíde por don Francisco de la Cueva de unos indios para asignárselos a un mercader:

"Y atento a que Juan Ortega es mercader, persona que ha mucho tiempo vive del trato, que ha ganado muchos pesos de oro y que no es casado ni tiene mujer ni hijos en esa provincia, ni es conquistador de ella..." 35.

Traficantes y mercaderes gozaron del favor de los gobernantes, quienes al encontrarse necesitados de algún producto español o pretenäiendo mayores beneficios en el corto tiempo que les era dado para su gobierno, hallaban buenos aliados en los profesionales del toma y daca. Pero, no siempre conquistadores y mercaderes estuvieron enirentados; éstos se convirtieron con frecuencia en el apoyo e'-onómico de aquella hidalguía de ultramar, hasta el punto $d$ s. que se puede afirmar que fueron sus fiadores, a pesar de los fuertes intereses que, por otro lado, los unían a los dirigentes. Así, en tiempos del presidente Landecho hallamos palabras como éstas en boca de los mercaderes, tratando de defender a los conquistadores para, de rechazo, poder cobrar sus deudas una vez que éstos hayan obtenido merced real:

"Sabe que los vecinos de csta ciudad viven pobremente con muchas necesidades, porque con las rentas que tienen no se pueden sustentar, según los grandes gastos y lo sabe porque es mercader y tiene cuenta con todos ellos y le deben muchos dineros y no los pagan por la necesidad que tienen y así les sobrelleva sus necesiciades de condolerse con ellos" 10.

35 A.G.I., Justicia, 1031-1-1. Pleito entre Ortega Gómes, vecino de Santiago y Don Pedro de Alvarado, 1537.

36 A.G.I., Guatemala, 111. Probanza sobre el número de vecinos de la ciudad de Santiago, 16 de noviembre de 1562 .

Anuario de Éstudios Americanos 
En definitiva, aunque la causa de enemistad entre conquistadores y mercaderes fue, como en otros casos, la encomienda, en realidad podemos decir que el fundamento de ella está en la política de los gobernantes, quienes usaron el poder a su antojo favoreciendo a unos y perjudicando a otros, según sus intereses y apetencias.

La mayor y más fuerte denuncia contra la arbitrariedad y el nepotismo de los gobernantes la hace el conquistador Cristóbal Lobo, quien, en varios documentos (cartas y probanzas), fechados entre 1549 y 1555, acusa a todos los gobernadores habidos hasta la fecha - Alvarado, Maldonado, Cerrato- y presenta poderes de hasta treinta vecinos y antiguos pobladores de Guatemala que tenían que haber sido preferidos en la concesión de indios «vacos», anteponiendo aquéllos, en cambio, a sus parientes, amigos, criados y paniaguados. Los acusa en los siguientes términos:

“...han procurado de maltratar a los que han servido al rey, porque ellos no tienen otras armas para pedir de comer sino decir que son conquistadores y por decir esto les toman odio y maltratan st.s personas..." ${ }^{37 .}$

$\mathrm{Y}$ añade que los conquistadores que él representa han sido agraviados por el presidente Cerrato «malciatándoles con palabras injuriosas y... llamando a los conquistadores robadores».

En el juicio de residencia de esic presidente, entre los cargos que se le imputan aparecen distintas ofensas infligidas a los conquistadores:

"...ha tratado mai y rigurosamente muchos vecinos diciéndoles con mucha ira y enojo palabras de injuria y afrenta. siendo vasallos de S.M., personas honradac, conquistadores y nobladores do esta tierra... diciéndoles públicamente que eran unos ladrones, bellacos, traidores, pizarreños, bebedores de sangre de indios y otras palabras de afrenta, y especialmente trató mal de obra y palabra a las personas siguientes:

...a Cristóbal Lobo le dijo que era un porquero y otras palabras de afrenta, siendo como es hombre honrado. regidor y conquistador de esta ciudad. A Cristóbal de Salvatierra, conquistador, persona honrada,

37 A.G.I., Patronato, 55, N.० 1, R.० 1. Expediente de Alonso de Vargas Lobo, 1574. 
porque le pedía de comer, conforme a como S.M. lo tiene mandado, le dijo que era un ladrón pizarreño, truidor y bebedor de sangre... A Tirado, el ciego, porque le pedía de comer como conquistador y poblador, casado y pobre, le dijo que se fuese con el diablo, que le había de dar cien azotes... A Martín de Guzmán, a Diego Holguín y a Juan de Alba dijo asimismo palabras de injuria..." 38.

Dejando al margen los insultos y acusacicnes, así como la personalidad y el temperamento de los individuos, se nos muestran burdamente pergeñados los intereses de los gobernantes. Lo que movía al rey a conceder mercedes a los conquistadores era precisamente la participación de éstos en la conquista; este hecho predisponía automáticamente al monarca en su favor. Por el contrario, el mismo hecho movía a ios gobernantes a odiarlos y «maltratar sus personas», ya que las encomiendas que ellos trataban de manejar a su antojo, repartiéndolas entre sus familiares $\dddot{y}$ amigos, habían de cederlas por orden real a los conquistadures.

Pero estos documentos a los que hago referencia, no sólo reflejan el antagonismo entre gobernantes y conquistadores en el aspecto económico, sino también en el social. En todos los insultos transcritos se afrenta a la persona del conquistador en su calidad de noble. Hay, parece, un desec manifiesto de rebajar la importancia social del grupo de conquistadores, nuevos hidalgos y, en algunos casos, hidalgo de ejecutoria. Es significativo el hecho de que entre los cargos que resultan contra Cerrato en su juicio de residencia sólo aparecen los insultos y vejaciones infligiáos por éste a los conquistadores, mientras que no hay ninguna denuncia de malos tratos a mercaderes, oficios ni, por supuesto, indios. En estc detalle podemos apreciar la conciencia de los conquistadores de pertenecer a un grupo digno de ser respetado por su situación de nobleza («...siendo como es conquistador») y el reconocimiento, diríamos oficial, de esta situación social privilegiada, puesto que no se toman como delitos graves los insultos y vejaciones hechos

38 A.G.I., Justicia, 183-1. Pleito entre Cristóbal Lobo y el presidente Cerrato, 9 de marzo de 1555. 
a otras personas hasta el punto de engrusar el capítulo de cargos en el juicio de residencia. En und publicación anterior ${ }^{39}$ consideraba que esta postura de desprecio de los gobernantes hacia los conquistadores era el equivalente a la competencia social y al desprecio que la noblesse de robe - juristas y letrados - de la Europa de la época hacen y sienten ante una hidalguía empobrecida y decadente; aunque, en el caso de Guatemala, habría que hablar de una hidalguía incipiente, pobre y con el agravante de no tener ejecutorias que la avalen. Para un presidente de la audiencia, licenciado o doctor, debería resultar etı́,jcsa la primacía socıal que el conquistador inculto, generalminte pobre y, hasta en algún caso analfabeto, trataba de tener subre el resto de la población sólo por el hecho de haber participado en la conquista.

Aunque el presidente Landecho comenzó su mandato (1558) favoreciendo a conquistadores y pobladores antiguos, al final de su gohicino (1561) se le acusa de las mismas faltas que se habían imputado a los presidertes que le precedieron: concesiones de ayudas de costa a parientes y criados, provisión de corregimientos y alcaldías mayores a personas recién llegadas a la tierra, «plateros, carpinteros y de otros oficios, mercaderes y tratantes, «así como a oficiales de la Audiencia, secretarios, relatores y procuradores»".

A principios del último tercio d.el siglo, estando en el gobierno don Antonio González como presidente (1568-1572) el cerrado grupo de conquistadores comenzó a establecer lazos de parentesco con otros grupos soriales a través de enlaces matrimoniales que, aunque no estuvieron sancionados favorablemente por aquéllos ni por algunos miembros del gobierno, fueron fomentados por el presiclente para beneficiar a sus deudos. Un encomendero denuncia en un memorial los casamientos concertados por don Antonio González: a una sobrina suya, moza de más de treinta años, que llevó con-

39 Sanchiz: Los bidalgos..., par. 103.

40 A.G.I., Guatemala, 45. Carta al zey de Alonso de Arteaga, 3 de febrero de 1561. 
sigo; a don Rodrigo, su cuñado, cor doña Inés Calderón, hija de importante conquistador y encomendero; a su sobrino con doña Beatriz de Escobar, viudì del regidor Francisco López, teniendo ésta más de cincuentáa años pero contando con mil quinientos pesos de renta al año; a un primo de su mujer con una "moza rica», hija de conquistador y encomendero, Juan de Alba... El presidente no dotaba a sus parientes para el matrimonıo, pero «¿qué niás dote quieren que en casándolos les envía a tasar sus repartimientos y se les acrecienta, y en cinco o seis años les vale más que la dote que él pudiera dar? ${ }^{41}$.

Uno de lo: gobernadores que más favoreció a los conquistadores y su' descendientes fuc el licenciado Briceño (1570-1573), quicn encomendó indic, en primera vida a los herederos que poseían tales encomiendas por segunda vida. Esta actuación de! presidente puso en su contra al fisco real, haciendo que se promoviesen varios pleitos contra sus beneficiados, puesto que por cédula real se prohibía a los gobernantes encomendar indios ${ }^{42}$.

Ya a fin de la centuria, los presidenies -Valverde (1578-1587) y Mallén de Rueda (1587-1594) — vuelven a ser acusados por el cabildo de beneficiar en las provisiones de cargos a sus deudos y criados en perjuicio de las personas que estaban nombradas para tales cargos ${ }^{43}$ y los descendientes de conquistadores repiten casi las mismas frases que años antes salían de boca de sus padres y abuelos, en sus continuas quejas contra los gobernantes:

"por los muchos méritos que de parte de nuestros padres y abuelos tenemos y por nuestras personas, pues ostentamos lo que ellos ganaron; antes tocándoles en esta tecla lo abomin ır y tratan ma! sin nos guardar preeminenci:i ninguna e impidiendo que no [sic] se haga informa-

41 A.G.I., Guatemala, 169. Memorial y declaración de Don Diegu de Guzmán, s.a.

42 A.G.I., Justicia, 292-1-4. Pleito entre el fiscal Artcaga Mendicla y Diego López de Villanueva, 1570. A.G.I., Guatemala, 9. Relación del fiscal de la audiencia, 1570.

43 A.G.I., Guatemala, 41. Capítulo de la ciudad de Santiago. 10 de febrero de 1590. A.G.I., Guatemala, 55. Autos de Don Diego de Herrera al rey, 6 de agosto de 1581. 
ciones con ameraza, diciendo que el que las hiciere lo ahorcarían con los informes al pescuezo...".

Y añaden lo que sus pasados decían:

“...hay hijos e hijas y nietos de conquistidores que han de ser preferidos en proveimientos y aprovechamientos para recompensarles los muchos y buenos servicios qua sus padres hicieron. Con ellos no se cumple $y$ mueren de hambre por dar el presidente los cargos $y$ aprovechamientos a sus deudos y criados" 44.

Pero los presidentes seguirán acuidiendo ć mil ardides e interpretaciones personales de las dispusiciones reales para tratar de justificar su acostumbrado neprotismo:

“...y la ordenanza de esta Audiencia r.o prohíbe al presidente y oidores en este caso otros deudos más que hijos, yernos, suegros, hermanos y cuñados y de éstos ninguno tengo yo" 45 .

PODER Y CONFLICTOS DE AUTORIDAD:

Gobernantes, ECLESIÁsticos, CONQUISTADORES Y COMERCIANTES

Nunca ha existido - ni creo que: exista jamás- plena concordancia entre io que individuos y grupos consideran su justo derecho dentro de una sociedad y la forma en que se distribuyen en ella riqueza, honor y poder. La sociedad colonial de Santiago no constituyó, precisamente, una excepción a esta cuasi ley social. En unos casos, el poder y los abusos de autoridad de las personas que los detentaban - presidentes, gobernadores y oidores de la audiencia - facilitaron su acceso, como hemos visto, a los biencs económicos y al status de los conquistadores, bien asignándose a sí o a sus deudos encomiendas, ayudas de costa o curregimientos, bien for-

44 A.G.I., Guatemala, 55. Carta al rey de Juan Méndez de Sotomayor, vecino y encomendero. 7 de abril de 1580 .

45 A.G.I., Guatemala, 10. El licenciado Mallén de Rueda al rey, 8 de marzo de 1592. 
zando los enlaces matrimoniales de aquéllos o sus descendientes con parientes o protegidns sujos.

Pero los conflictos no se redujeron al enfrentamiento cntre conquistadores y gobernantes. Diversos grupos e individuos frustrados de aquella sociedad se esforzaron por aumentar su parte de gratificación en ella; sus demandas encontraron siempre la resistencia de aquéllos que, como los conquistadores, habían establecido previamente sus intereses en relación con la distribución de bienes, honra y prestigio. Por ello, durante toda la centuria (sigio XVI) sufrirán ataques del resto de la sociedad, unas veces encubiertos con justificaciones humanitarias y cristianas - caso de los religiosos con respecto a las er:comiendas y el trabajo del indios para con su encomendero- otras, directainente, exigiendo sus mismas prerrogativas económicas y sociales - caso de artesanos y comerciantes-; y... vistos todos estos ataques por el conquistador, naturalmente, como una anıenaza al sistema mismo, al orden social establecido y querido pur la Corona española.

No todos los conflictos, sin embárgo, alcanzaron la misma magnitud y algunos se resolvieron desde Íos ámbitos oficiales y legales; esto ocurrió con el disfrute de las encomiendas. Aquellos no llegaron a las tierras recién conquistadas con el deseo de encontrar nuevos horizontes en la práctica de sus oficios, sino con el ánimo dispuesto a convertirse en señores; por esta razón piden repartimientos de indios y se les conceden, bajo la ameisaza de no practiciar sus oficios. Una vez obtenidas sus encomiendas, abandonaron sus trabajos y comenzaron a vivir como «caballeros», manteniéndose sólo con los beneficios de estos repartimientos. Posieriormente, una cédula real, precedida de protestas varias de la ciudad, manda que se despoje a estos individuos de ios indios a fin de que se dediquen a sus antiguos oficios. He aquí como relata el cronista Remesal el conflicto que mantuvo desasistida a la ciudad entre los años 1530 y 1534 : 
"Acariciados, pucs, y honrados los oficiales de la ciudad de Santiago, más que otro ninguno del Viejo Munto, dieron las riquezas y hacienda su fruto, que fue entonación y sobarbia y desdeñarse de lo que antes eran. El herrero apagó la fragua, el sastre cerró la tienda... el zapatero no conocía las hormas y para sí mismo enviaba pcr zapatos fuera de la ciudad. El carpintero huía de !a zzuela y trataba de jaeces y caballos y que otro hiciese las obras de la siudad y se afrentaba de que le dijesen que había aserrado un madero .." 4 .

Los oficiales mecánicos, una vez desposeídos de sus encomiendas, no obstaculizaron los intereses de los conquistadores, puesto que, conocido por todos el trabajo que aquéllos desempeñaban, no podían aspirar al status sorial del conquistador; sólo en algunos casos, por favu:es realizados a los gobernantes, recibieron las encomiendas o ayudas que debieron estar destinadas " los conquistadores. No obstante, éstos no pudieron desterrar la profunda apetencia que afectaba a todos los que llegaban a Guatemala y, yo diría que a todas las Indias: el ennoblecimiento.

Conquistadores, antiguos pobladiores y sus descendientes se encargaron de controlar, desde que se produjera el conflicto, las ambicion $є s$ de artesanos y comcrciantes «de menudo» (pequeños comerciantes) desde sus puestos de cabildo, regulando sus jornales, los precios de las manufacturas y de los productos que se vendían en los mercados de la ciudad, a la vez que mantuvieron el privilegio de examinar a los nuevos artesanos ${ }^{47}$.

El «mercadeo» fue considerada : na ocupación indigna por los españoles, importantes de Sartiago en los primeros años de la vida colonial; éstos se encargaron de abastecer la ciudad de trigo, carne de res o de cualquier producto procedente de sus tributos (adquiridos por servisio o en especie) sin ser considerados por ello mercaderes o tratantes; nunca perdieron el apelativo de encomenderos y su actividad comer-

46 Remesal: Historia..., T. II, págs. 435 y 436.

47 Por una cédula del 10 de marzo de 1566 se mantiene al cabildo el privilegio de examinar a los oficiales de sus oficios. Las primeras ordenanzas dictadas por el ayuntamiento para la constitución de los gremios de herreros y sastres son de 1530. 
cial se encubría bajo la justificación eufemística de extra dedicados a «sus granjerías», aunque ello inimplicase eí que algunas de esas «granjerías» (cacao, azúcar, etc.) se vendieran en México y España. En el último cuarto dəl siglo XVI, la dismirución de las encomiendas - casi todos los pueblos del valle pasaron a ser tributarios de la Corona- y las crecientes necesidades de lujo y bienestar de la publa: ón española dieron lugar a la aparición de un grupo social jederoso; los «mercaderes de grueso»; éstos comerciabar. con productos de la metrópoli y sus re.uas llegaban hasa ei Golfo Dulce o traspasaban las fronteras de la gobernación hasta llegar a México, para vender allí sus mercancías i) enviarlas desde el puerto de Veracruz a España. A su vez, eitos ricos comerciantes surtían de ropas y productos de Casiilla a los españoles en general y a los «comerciantes de meaudi »», españoles y, ya entrado el siglo XVII, mestizos, quienes mantenían tiendas abiertas al público, vendiendo no sólo a los españoles, sino a indios, mulatos, mestizos e, incluso, negros libres, a los que surtían de tejidos, huipiles, mantas y cualquier otro artículo manufacturado procedente de Oaxaca, rhiapas, Yucatán o Mé. xico ${ }^{48}$.

Sin embargc, las ventas casi nunca se renilzaban de forma directa; se establecían cadenas interminables de vendedores y revendedorcs, haciéndose siempie las transacciones a través de agentes o terceras personas. Encubiertamente, vecihos importantes e incluso miembros de la audiencia y el rahildo realizaban tratos comerciales para aumentar sus ingresos; aún más, algunos clérigos se convertían en tratantes y sus actividades romerciales se centraban directamente en los indios, aunque siempre el «trato» fuese realizado por intermediarios servidores suyos (españoles, indios, mestizos y nuulatos).

El comercio, pues, actividad considerada infamante por los conquistadores y antiguos pobladores y la que, no obs-

48 Los testamentos son una fuente importante para conocer la actividad de estos comerciantes: qué vendían y a quiénes, procedencia de sus productos, deudas, etc. 
tante, todos se veían obligados a realizar de forma encubierta para obtener bereficios sin «perder la honra», adquiría importancia y distinción cuando pasaba de «menudo» a «grueso» $y$, sobre todo, cuando se comerciaba con productos de lujo procedentes de Castilla.

La paulatina desaparición de las encomiendas y las fortunas de estos mercaderes «de grueso» rompió las fuertes barreras sociales establecidas por el grupo de conquistadores. Antiguos detractores de aquéllos, en la necesidad de mantener su «presencia honrosa» y ya desaparecidas las encomiendas, que habían sido motivo de conflictu entre ambos grupos - por las generosas concesiones que de :llas hicieran los gobernantes en favor de dichos mercaderes-, los conquistadores tuvieron que pactar con la riqueza para mantener su nobleza, estableciendo alianzas matrimoniales con aquéllos. Por medio de estos matrimonios los descandientes de conquistadores obtuvieron la base económica sustentadora de «la reputación en que estaban», mientras que los ricos mercaderes consiguieton añadir a sus saneadas haciendas el prestigio y la notoriedad de los conquistadores-hidalgos guatemaltecos.

Quizás el más fuerte antagonisn:o que encontraron los conquistadores partiese de los religiosos. Los frailes luchaban en buena parte por aliviar é férreo yugo que aquéllos como encomendstos, ponían a los inuígenas para su explotación en beneficio propio; pero, sus continuas protestas ante c.] rey y la audiencia no sólo comportan el deseo de proteger al indio, sino de encubrir sus intereses en conflicto con el resto de población española por el dominio y el monopolio sobre la persona del indígena.

Parece que ios religiosos aprovecharon la puesta en práctica de las Leyes Nuevas para enfrentar a la población indífena con el grupo de conquistadores, a fin de aumentar su propio prestigio entre los indios; aquéllos, por su parte, acusan a los religiosus de engañar en las tasaciones y de apropiarse de indios y tierras. En una probanza contra frailes, un testi- 
go, vecino de Sautiago pero no encomenderu, declara haber visto cómo al ir la audiencia a «contar los indios de los pueblos, los frailes dominicos hacían huír de cien a doscientos de ellos para que así no tuviesen que tributar a S.M. o a los encomenderos», :juedando libres, por tanto, para el aprovechamiento de ios religiosos. En la misma probanza, un clérigo acusa a los frailes de «usar tanto poder como el Papa y más que el Rey y su Audiencia, al despojar y expulsar a los clérigos de tierras en las cuales ivabían sido puestos por el mismo obispo; por esta cuestión hubc un escandaloso enfrentamiento armado cntre clérigos y fruiles ${ }^{49}$.

Apoyados por sucesivos presidentes de la audiencia, los frailes no sólo se opusieron a los encomender(ı, sino también a los clérigos, a los que intentaron una y otra vez despojarlos de los pueblos de indios que les habian sido encomendados para su evangelización. En 1553 un provincial de Santo Domingo, fray Tomás de la Torre, escribe al rey solicitando que se expulse de los puebilos de doctrina a dichos clériros y se permita a los religiosos instalarse en ellos. Las razones que esgrime en su petición se tepetirán en boca de jos religiosos: «no hay lustre de policía ni de cristiandad»; «ios clérigos sólo acuden a los pueblos para aprovecharse de los indios y mercadear».

En tiempos del presidente Cerrato, el cabildo de Santiago -constituido por conquistadores y antiguos pobladoresen sus continuas quejas contra el r resicente, culpa también a los frailes de la situación de despoblaciśn y pobreza en que se hallaba Guatemala:

"Orden ni justicia...no la hay y la que había la ban quitado él y los frailes, por quienes él se ha gobernado. Si los españoles faltan, ni los frailes ni la Audiencia sustentarían 'a fo" 80 .

Las diferencias y competencias entre frailes y sacerdotes seculares fueron continuas durante toda la centuria e de 1562 .

49 A.G.I., Guatemala, 45. Probanza ante la justicia de Guatemala. 20 de noviembre

50 A.G.I., Guatemala, 41. El cabildo de Guatemala al rey, 12 de marzo de 1552. 
hicieron intervenir frecuentemente a la Corona para recomendar a los obispos que mediasen eil dichos enfrentamientos ${ }^{61}$. Sin embargo, tod'ss los documentis:s de la época muestran una población dividida en dos facciones: una compuesta por los conquistadores, antiguos pobladores, clérigos y obispos y otra que unía en sus intereses al presidente, miembros de la audiencia y religiosos de diversas órdenes. El indio, su protección o explotación constituyó la causa aparente de un conflicto en el que medían sus fuerzas el poder político y el eclesiástico (obispos-gobernartes) y en su lucha por imponer su autoridad, apoyaron los intereses de las órdenes reljgiosas (gobernantes) y de los sacerdotes seculares (obispos). Pero, ¿cuál fue la razón que mantuvo unidos a conquistadores y eclesiásticos? Las prebendas y los beneficios-curatos constituían una buena solución a los problemas familiares de índole económica; remedio para las madres viudas y las hermanas pobres $\mathrm{y}$ por casar. Y, para conseguirlos, ser descendientes de conquistador o poblador antiguo eran méritos más que suficientes ${ }^{52}$.

Hacia fines del siglo el clero iecular tenía bajo su tutela mayor cantidad de indios que cualquiera de las órdenes religiosas asentadas en Guatemala ${ }^{53}$. Poco a puro los clérigos habían ido sustituyendo a los frailes en los pueblos de indios que, a su vez, dejaron de depender de los encomenderos para pasar a ser tributarios de la Corona. Ya eil 1586, debido a la polémica que durante todo el siglo habían mantenido los defensores de clérigos y frailes en relación con el adoctrinamiento de los indios, el rey pide al cabildo secular de Santiago su opinión acerca de esta materia. Sorprendentemente, no hay unanimidad en la respuesta: unos upinan en tavor de los frai-

51 Véase, por ejemplo, la ct́dula dirigida a los obispos de Guatemala, Chlapas y Honduras en 1558. A.G.I., Guatemala, 169.

52 A.G.I., Guatemala, 171. Propuesta que hace el obispo de Guatemala para los beneficios curatos.

53 A.G.I., Guatemala, 39. En 1575, según documentución consultada, exintín en el obispado de Guatcmala un total de 56.000 indios casados, cuys evangelización se repartla entre el clero regular y el secular de la siguiente forma: 30.000 correspandían a los clérigos, 12.000 a los franciscanos, 8.000 estaban a cargo de los dominicos y 6.000 al de los mcrcedarios. Descripción de los corregimientos que ha de haber en la sobernación de Guatemala, año 1575. 
les, «porque castigan más a los inclios por los pecados públicos y las borracheras»; otros, en cambio, apoy:nn a los clérigos, pues - dicen- «quitarlos es quitarles el pan a los hijos de los conquistadores que nacieron en !a tierra y que a veces mantienen a sus padres y hermanos..." $"$ "t

Desde lueg:, no es tarea dei historiador emitir juicios sobre la eficacia y honradez de los clérigos y religiosos de la Guatemala colonial, pero sí explicd: los comportamientos y juicios de los hombres del pasado, acudiendo para ello a las circunstancias económicas, sociales y políticas que dirigían sus acciones y valoraciones. Es así como podemos comprender por qué el cabildo secular, años atrás compuesto exclusivamente de conquistadores y pobladores antiguos, y defensor entonces del clero secular, se halle dividido a tin de la centuria respecto a sus opiniones sobre el clero, pues, no hay que olvidar que en estas tardías fechas la mayor parte de los cargos de cabildo habían sido ocupados por españoles recién llegados de la península, sin intereses en la tierra, o por meros vecinos, carentes de un pasado honroso.

Por otra parte, la buena relación mantenida durante años entre gobernantes y religiosos se rompe en estos últimos años de la centuria. Así, curiosamente, la o:den religiosa que más favor obtuvo en tiempos del presidente Cerrato, los dominicos, caen en desgracia durante la presi:!encia de Valverde ${ }^{55}$. ¿Qué había ocurrido pata cambiar la actitud de los gobernantes respecto a los dominicos? Estos, ensoberbecidos por la fuerza y razón de fray Bartolomé de las Casas ante la Corona, des4 reciaban a las autoridades civiles, haciendo oidos sordos a sus mandamientos y recomendaciones, actuando libremente en los pueblos a ellos encomendados para :u evangelización y tomando las atribuciones de aquéllas.

De la nueva situación y las nuevas alianzas, quienes, desde luego, no se beneficiaron fueron ins indics; pues, si no

54 A.G.I., Guatemala, 171. El cabildo secular de Guatemala al rey, 1586.

55 A.G.I., Guatemala, 55. Don Diego de Herrera al rey, 6 de egosto de 1581. 
habían de servir y tributar al encumendero, a! fraile, al clérigo o a todos juntrs, tenían sobre sus espaldas el mantenimiento del presidente, oidores, alcaldes ordinarios, corregidores, alcaldes mayores, de la Mesta, de la Hermandad... Y, en respuesta a estas presiones, los indios abandonakan sus milpas, sus casas y sus comunidades, pasando a aumentar el número de mendigos y vagabundos que pululaban por la ciudad y sus alrededores ${ }^{56}$. Por otra parte, las diferencias y enfrentamientos que las distintas órdenes religiosás mantuvieron entre sí y con los sacerdotes seculares, - - - -nsecuencia de la lucha por mantener el control sobre los indios- les llevó a posiciones contrapuestas en la transmisión de la doctrina cristiana, a la vez que obligaba a los indios a seguir o apoyar a unos en contra de los otros

Otra enfermedad, sin embargo, aquejaba a la población de Santiago en su primer siglo de vicia colorial, que enfrentaba asimismo a unos vecinos contra otros, convirtiendo aquella sociedad en !na de las más cuifflictivas de la época: me refiero a las disputas suscitadas por mantener el status, por derender e imponer puntillosamente los tratamientos y títulos, tanto los que legalmente correspondían como los que no. En ¿quella sociedad de apariencia - como la he calificado en una publicación anterior ${ }^{57}$-, gran parte cic las dispıtas y enfrentamientos de la población tenían cumo causa el no haber sido tratados unos y ctros de acuerdo son la «calidad de sus personas». Así, unos pecan por exceso, atribuyéndose el tratainiento de señorías, como es el caso de los alcaldes y regidores del cabildo ${ }^{5 x}$, y otros lo hacen por defecto, naturalmente, en su tratamiento a los otros. Cientos y cientos de pa-

\footnotetext{
56 Para mayor información sobre el trabajo de los indios, consúltese: Sanchiz: Cambio en la estructura familiar indigena...

57 Los hidalgos...

58 A.G.C., A1.4698.40637. «Estando prohibido por pragmática real que en ningún cabildo de ciudad que no sea cabeza de reino se pueda llamar, ni escribir, ni intitular Señoría, los dichos alcaldes y regidores, en quebrantamiento de ello se han llamado e intitulado y consentido llamar señorías en su ayuntamiento, por escrito y de palabra». Memoria de los cargos que se hacen a los alcaldes y regidores y demás oficiales de república, 1575-1598.
} 
peles, pleitos interminables se promovieron por no guardar$\therefore \epsilon$ las preeminencias que con ciertas personas se debían: un sitio especial en la catedral, en las procesiones o festejos, no llamar a otro de «Don», o saludar incorrectamente... Es difícil a la mentalidad del siglo veinte llegar a comprender la gravedad de tales delitos; pero, si pensamos que en aquella época se era lo que se mostraba y decía ser con el refrendo, naturalmente, del resto de la sociedad, podiemos entender mejor la importancia de tales hechos.

Para finalizar este breve análi:isis de los conflictos suscitados en la Guatemala del siglo XVI, así como sus causas, nada mejor que acudir a la exposición que el oider Tomás López hace de los defectos que aquejaban a aquella sociedad:

"Pero, ¿qué diré a Vuestra Magestad? No le han tocado al seglar, ni al eclesiástico, ni al otro, ni al otro en el calcañar, por dicha con descuido, cuando salta y respinga haciendo fieros que se las nagará. que escribirá a Vuestra Magestad, que Je perseguirán" 60.

\section{Pilar Sanchiz Ochoa}

59 A.G.I., Guatemala, 9. El oidor Tomás López al rey. 18 de marzu de 1551. 